\title{
Phylogenetic analysis of mitochondrial DNA in Japanese pedigrees of sensorineural hearing loss associated with the A1555G mutation
}

\author{
Satoko A be ${ }^{1}$, Shin-ichi U sami ${ }^{1}$, H ideichi Shinkawa ${ }^{1}$, M ike D Weston $^{2}$, Larry D \\ O verbeck ${ }^{2}$, D enise M Hoover ${ }^{2}$, Judy B Kenyon ${ }^{2}$, Satoshi $\mathrm{Horai}^{3}$ and William J \\ Kimberling ${ }^{2}$ \\ ${ }^{1} D$ epartment of O torhinolaryngology, $\mathrm{H}$ irosaki U niversity School of M edicine, Japan \\ ${ }^{2} \mathrm{D}$ epartment of G enetics, B oys Town N ational Research H ospital, O maha, NE, USA \\ ${ }^{3} \mathrm{D}$ epartment of B iosystems Science, The G raduate U niversity for A dvanced Studies, Hayama, K anagawa, Japan
}

Thirteen Japanese families (ten of which were from the northern part of Japan), with sensorineural hearing loss associated with the 1555 A to G (A1555G) mitochondrial mutation, a known cause of non-syndromic hearing loss, were phylogenetically analysed using data obtained by restriction fragment length polymorphism (RFLP) and D-loop sequencing of mitochondrial DNA (mtDNA). Various types of mtDNA polymorphism were detected by restriction enzymes and D-loop sequence. No common polymorphic pattern throughout the 13 families was found, though three families exhibited the same restriction patterns and the same sequence substitution in the D-loop. To find where each of the 13 families are situated in the phylogenetic tree, the 482-bp of D-loop sequence were compared with those of 62 normal Japanese subjects. Despite the three families mentioned above appearing to be clustered, the remaining 10 families were scattered along the phylogenetic tree. This indicates that there was no common ancestor for the 13 Japanese families bearing the A1555G mutation except three families, and that the A1555G mutation occurred sporadically and multiplied through evolution of the mtDNA in Japan. The present results showed that the common pathogenicity (hearing loss associated with the A1555G mutation) can occur sporadically in families which have different genetic backgrounds, even in the Japanese population.

Keywords: phylogenetic analysis; polymorphism; mitochondrial DNA; D-loop; sensorineural hearing loss; aminoglycoside

Correspondence: S U sami, D epartment of O torhinolaryngology, Hirosaki U niversity School of Medicine, 5 Zaifu-cho, H irosaki 036-8562 Japan. Tel: 8117239 5099; Fax: 8117239 5100; E-mail: usami@cc.hirosaki-u.ac.jp

R eceived 9 February 1998; revised 6 M ay 1998; accepted 22 M ay 1998 


\section{Introduction}

$M$ itochondrial mutations are known to be a factor in non-syndromic sensorineural hearing loss (SNHL). A mong them, the $A 1555 G$ mutation has been reported to cause susceptibility to aminoglycoside induced hearing loss. $^{1-3}$ A ccording to our clinical studies ${ }^{4}$ this mutation causes $\mathrm{SNHL}$ even without aminoglycoside exposure.

This mutation was first reported within populations in restricted areas, including A rab-I sraeli, Chinese, and Japanese. $^{1-3}$ The regional predominance in A sian populations has lead us to hypothesize that there was a common ancestor of such families with the A $1555 \mathrm{G}$ mutation. However, recent reports demonstrate that this mutation has also been found in Greek, English/ I rish, I talian, M exican, Puerto R ican, and Vietnamese, ${ }^{5}$ Zairean, ${ }^{6}$ Spanish, ${ }^{7}$ and Mongolian populations. ${ }^{8}$ This suggests that the A $1555 \mathrm{G}$ may exist all over the world. This widespread existence of the $A 1555 G$ mutation gave rise to an interesting question as to the origin of the A $1555 G$ mutation. W ith regard to occurrence of this mutation, phylogenetic analysis of 10 independent families with the A $1555 \mathrm{G}$ mutation from A frica and A sia indicated it had multiple origins, occurring on each racial-specific mtD NA haplotype. ${ }^{9} \mathrm{H}$ owever, there still remains a question as to whether this mutation occurs sporadically even within individual racial populations or occurs on some specific haplogroups within individual populations (eg Japanese). Within the A sian populations the A $1555 G$ mutation has been reported to occur predominantly on a specific haplogroup, which is rare in the Caucasian population. ${ }^{10} \mathrm{H}$ utchin and Cortopassi postulated that the type II haplogroup ${ }^{10}$ may have the potential risk for deafness. We therefore examined whether the A $1555 G$ families belong to some specific haplogroups.

Polymorphism found in Japanese pedigrees was studied on the basis of

1) restriction enzyme analysis (restriction fragment length polymorphism - RFLP),

2) the presence of the 9-bp deletion, which is known to be a valuable marker in examining populations with A sian affinities, ${ }^{11,12}$ and

3) the sequence of the D-loop region, which is more rapidly evolved than other parts and therefore more variable and a useful evolutional marker. ${ }^{13}$

The polymorphism of the $13 \mathrm{~J}$ apanese families revealed by the present study provided informative results as to the origin of the $\mathrm{A} 1555 \mathrm{G}$ mutation within the Japanese population.

\section{Materials and Methods}

Samples

Blood samples obtained with informed consent from 13 subjects from 13 Japanese families (one subject per family) with the A $1555 \mathrm{G}$ mutation were used in the present study. Ten families originated from A omori Prefecture, in the northern area of the main Japanese island, one family from Tokyo, in the central part of Japan, and two families from Kumamoto Prefecture, in the southern area. The control samples were from 62 subjects from the main island of Japan. ${ }^{14}$ Total genomic DNA was prepared by means of a GENOMIX K it (Talent, Trieste, I taly).

\section{The A1555G Mutation}

The A 1555G mutation was identified as previously described. ${ }^{4}$ In brief, PCR products (the nucleotide of 1252 to 1726) were digested with the restriction enzyme (A Iw 26I), electrophoresed and visualised on an agarose gel. The 1555 mutant mtDNA was visualised as the loss of a restriction enzyme site. The PCR-amplified products were also sequenced with an $\mathrm{ABI}$ sequencer $373 \mathrm{~A}$ (Perkin EImer Co $L$ td, Foster City, CA , U SA ) to confirm the conversion of the nucleotide of 1555 from $A$ to $G$.

\section{Restriction Enzyme Analysis}

A mplification of mtD NA by PCR was carried out using 7 sets of primers according to Torroni et al. ${ }^{15} 5^{\prime}->3^{\prime}$ primer coordinates for R FL P analysis were as follows (upper, lower): (533-553, 722-701), (5140-5161, 5469-5451), (10280-10298, 10548-10529), (13200-13219, 13537-13518), (16286-16306, 16547-16529), (8196-8215, 8316-8297), (7888-7908, and $8288-8310)$. The Cambridge R eference Sequence ${ }^{16}$ was used for primer design.

The PCR was performed in a Perkin E Imer 9600 thermocycler using $200 \mathrm{ng}$ genomic DNA, 10-1000 pmol of each primer, 1-2 $\mathrm{mM} \mathrm{MgCl} 2,2 \mathrm{mM}$ dNTP, $10 \times$ buffer, $5 \mathrm{U}$ Taq $\mathrm{G}$ old (Perkin E Imer, Foster City, CA , U SA ) and enough $\mathrm{H}_{2} \mathrm{O}$ to create a $100 \mu \mathrm{l}$ PCR reaction mixture. Ten minutes preheating at $95^{\circ} \mathrm{C}$ was followed by 35 three-step cycles $\left(95^{\circ} \mathrm{C}\right.$ for $30 \mathrm{~s}, 55^{\circ} \mathrm{C}$ for $1 \mathrm{~min}, 72^{\circ} \mathrm{C}$ for $1 \mathrm{~min}$ ) ending with $10 \mathrm{~min}$ at $72^{\circ} \mathrm{C}$ in a Perkin $\mathrm{E}$ Imer/C etus thermal cycler. A mplified fragments were digested with eight restriction enzymes (A lul, $\mathrm{D}$ del, $\mathrm{H}$ ael II, $\mathrm{H}$ incl I, R sal , A val I, Sau3A I, and Taql ), ${ }^{15,17-19}$ electrophoresed on 2-3\% agarose gels stained with ethidium bromide, and observed under UV light.

\section{The 9-bp Deletion}

$M$ itochondrial DNA 9-bp deletion of one of the two tandem repeats (CCCCCTCTA) between nt 8272 and 8289 within the COII/tR NA ${ }^{\text {(Lys) }}$ region ${ }^{11,12,20}$ was examined. Fragments including the 9-bp deletion region were amplified using primers nt $8196-8215$ and nt $8316-8297 .{ }^{12}$ The PCR products were electrophoresed using $6 \%$ polyacrylamide gels $(40 \%$ acrylamide stock fluids, $1 \times$ TBE, TEMED, $10 \%$ APS, 18 hours). A fter staining with ethidium bromide, the length of these fragments were visualised by U V light. 


\section{DNA Sequencing}

The D-loop region is located at 16024-16569 and 1-648. To amplify the D-loop region, primer pairs (nt15945-15969, 748-767) were used for PCR. The nucleotide sequence was determined by using a dye termination method. For sequencing the large fragments, a series of 8 primers was used. Primers for $D$-loop region sequencing were as follows $\left(5^{\prime}->3^{\prime}\right):$ 15945-15965, 16238-16257, 16560-10, 316-335, 767-748, 452-432, 130-111, and 16389-16329.

\section{Phylogenetic Analysis}

The nucleotide sequences of a 482-bp fragment of the $D$-loop region (positions 16129-16569 followed by positions 1-41 in the reference sequence of $A$ nderson et $\mathrm{al}^{16}$ ) from the present family subjects together with 62 normal subjects ${ }^{14}$ were aligned and compared. The number of nucleotide substitutions per site between individual sequences was estimated by the Kimura two-parameter model of nucleotide substitutions. ${ }^{21} \mathrm{O}$ the basis of the estimated number of nucleotide substitutions, a phylogenetic tree was constructed using the unweighted pair-group method with arithmetic mean (UPGMA). ${ }^{22}$

\section{Results}

Table 1 summarises polymorphism of mtD NA in all 13 pedigrees revealed by

1) restriction enzyme analysis,

2) the presence of 9-bp deletion, and

3) sequence substitution between nt 1252 and 1726 by means of direct sequencing.

Various patterns revealed by the RFLP analysis were evident. A mong the 13 families, 5 families (N os 1, 2, 6, 11 and 12) showed identical patterns with regard to the
RFLP analysis. The 9-bp deletion was found in 6 families $(1,2,6,11,12$ and 13). D irect sequencing confirmed the A $1555 \mathrm{G}$ mutation for all the families. In families 7 and 9 , the $\mathrm{A} 1382 \mathrm{C}$ mutation was also found, but no other mutations between nt 1252 and 1726 were revealed in our samples. Whilst each family showed two to six mutations, no mutated site except for the A $1555 \mathrm{G}$ mutation was common among all 13 families (Table 1)

Table 2 shows mutations found in the $D$-loop region by direct sequence analysis. A total of 45 mutations were found and each family possessed an average of 11.4. The A 73G and A $263 \mathrm{G}$ mutations were common among the families studied. Three families ( 1,2 and 6$)$ out of the five mentioned above (families 1, 2, 6, 11 and 12) showed the same set of mutations.

$M$ ean pairwise divergences of total $D$-loop between all families were calculated to be from 0 to $1.59 \%$ (mean $1.11 \%$ ). In the most variable part in the D-loop (16024-16393), the sequence divergence was from 0 to $3.51 \%$ (mean $2.13 \%$ ).

Figure 1 shows the phylogenetic analysis of the 13 families by comparison of 482-bp of D-loop sequences in them with those of 62 normal Japanese subjects. ${ }^{14}$ The 13 families were not clustered but were scattered along the phylogenetic tree.

\section{Discussion}

Mitochondrial DNA polymorphism of Japanese has been demonstrated using various restriction enzymes as

Table 1 Polymorphism in 13 families

\begin{tabular}{|c|c|c|c|c|c|c|c|c|c|c|c|c|c|c|}
\hline & $\begin{array}{l}- \text { A lul } \\
5176\end{array}$ & $\begin{array}{l}\text { +Alul } \\
10397\end{array}$ & $\begin{array}{l}\text { +A lul } \\
13262\end{array}$ & $\begin{array}{l}\text { +D del } \\
10397\end{array}$ & $\begin{array}{l}+\mathrm{H} \text { ael II } \\
663\end{array}$ & $\begin{array}{l}\text { +H ael II } \\
16517\end{array}$ & $\begin{array}{l}\text {-H inel I } \\
13259\end{array}$ & $\begin{array}{l}\text {-H inel I } \\
16329\end{array}$ & $\begin{array}{l}\text { 9bp } \\
\text { deletion }\end{array}$ & $\begin{array}{l}\text { +A val I } \\
8249\end{array}$ & $\begin{array}{l}\text { +Sau3A I } \\
8019\end{array}$ & $\begin{array}{l}\text { +Taql } \\
8022\end{array}$ & $\begin{array}{l}1382 \\
A \rightarrow C\end{array}$ & $\begin{array}{l}1555 \\
A \rightarrow G\end{array}$ \\
\hline Family 1 & - & - & - & + & - & + & - & - & $D$ & - & - & - & - & + \\
\hline Family 2 & - & - & - & + & - & + & - & - & $D$ & - & - & - & - & + \\
\hline Family 3 & - & - & - & - & + & - & - & - & $\mathrm{N}$ & - & - & - & - & + \\
\hline Family 4 & - & - & - & - & + & + & - & - & $\mathrm{N}$ & - & - & - & - & + \\
\hline Family 5 & - & - & - & - & - & + & - & - & $\mathrm{N}$ & - & - & - & - & + \\
\hline Family 6 & - & - & - & + & - & + & - & - & D & - & - & - & - & + \\
\hline Family 8 & - & - & - & + & - & - & - & - & $\mathrm{N}$ & - & - & - & - & + \\
\hline Family 9 & - & - & - & + & - & + & - & - & $\mathrm{N}$ & - & - & - & + & + \\
\hline Family 10 & - & - & - & + & - & - & - & - & $\mathrm{N}$ & - & - & - & - & + \\
\hline Family 11 & - & - & - & + & - & + & - & - & D & - & - & - & - & + \\
\hline Family 12 & - & - & - & + & - & + & - & - & D & - & - & - & - & + \\
\hline Family 13 & - & + & - & + & - & - & - & - & D & - & - & - & - & + \\
\hline
\end{tabular}

Polymorphism found in 13 families associated with the A 1555G mutation, defined by 8 restriction enzymes, the presence of 9-bp deletion, and the sequence substitution between nt 1252 and 1726. Thirteen families showing various polymorphic patterns, with an identical pattern in five (families 1, 2, 6, 1 and 12).

+: mutated, - : not mutated, $\mathrm{D}$ : the presence of 9-bp deletion, $\mathrm{N}$ : the absence of 9-bp deletion. 
Table 2 Sequence substitution in the D-loop region

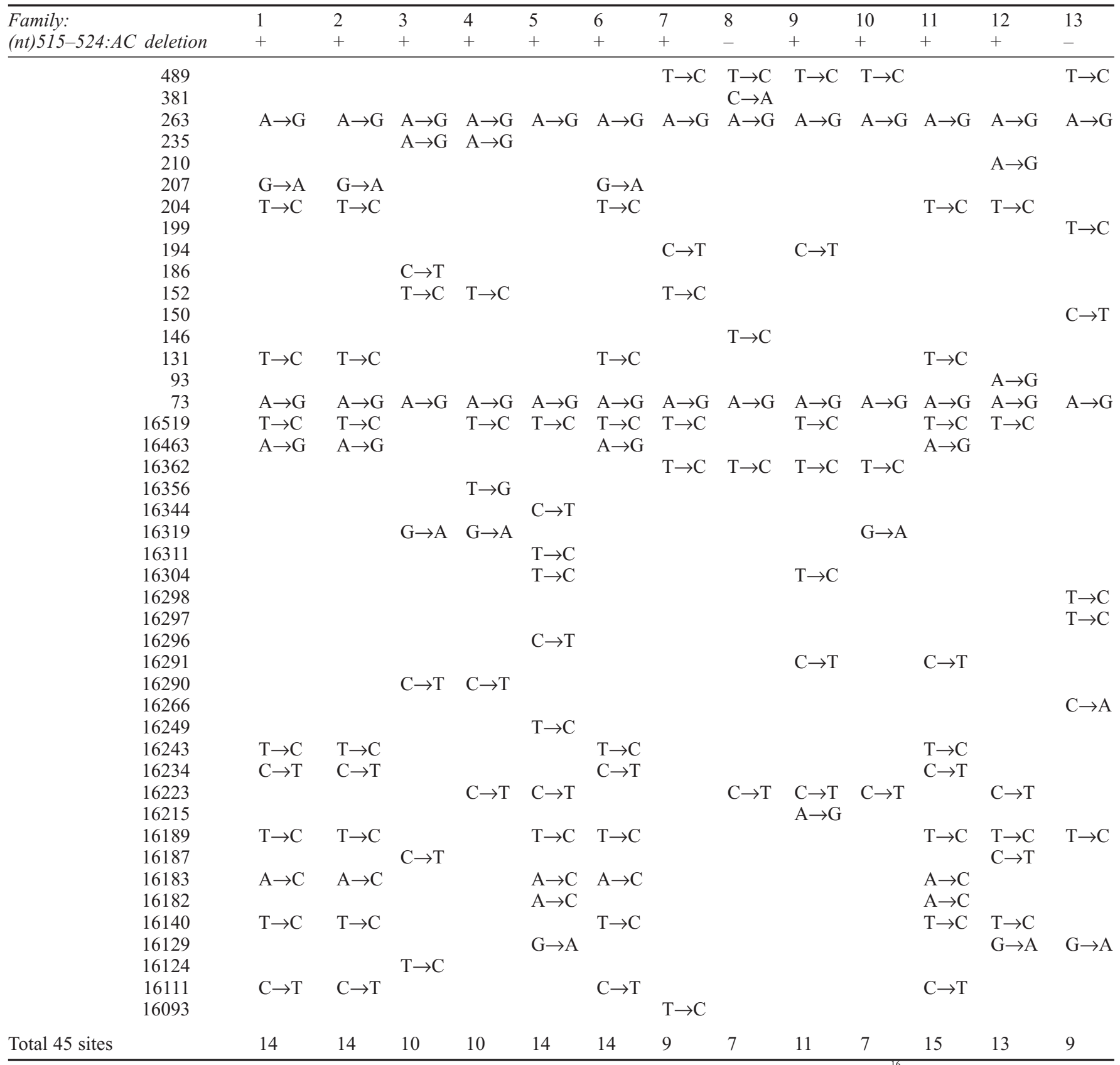

The sequence substitution found in the D-loop region (compared with the sequence reported by Anderson et al ${ }^{16}$ ). Each family shows 7-15 polymorphic sites. No common substitution pattern is evident except for families 1, 2 and 6 .

well as D-loop sequence. ${ }^{17,20,23,24} \mathrm{~A}$ series of observations revealed the characteristic features of Japanese ethnic background. H orai et al ${ }^{17}$ classified 62 different combinations of restriction types by using 9 restriction enzymes, and showed a clear separation into two major clusters (groups I and II). This grouping was also compatible with the phylogenetic analysis using $D$-loop sequence. ${ }^{14}$ The thirteen families were examined to see which haplogroup they belonged to by various restriction sites as well as D-loop sequences. A Ithough R FLP indicated that there were completely identical patterns in five families (Table 1, families 1, 2, 6, 11 and 12), there were no common polymorphic patterns within the 13 families. A ccording to the above classification (group I/II), families 1, 2, 6, 11 and 12 belong to group I. Since the other eight families belong to group II, the 


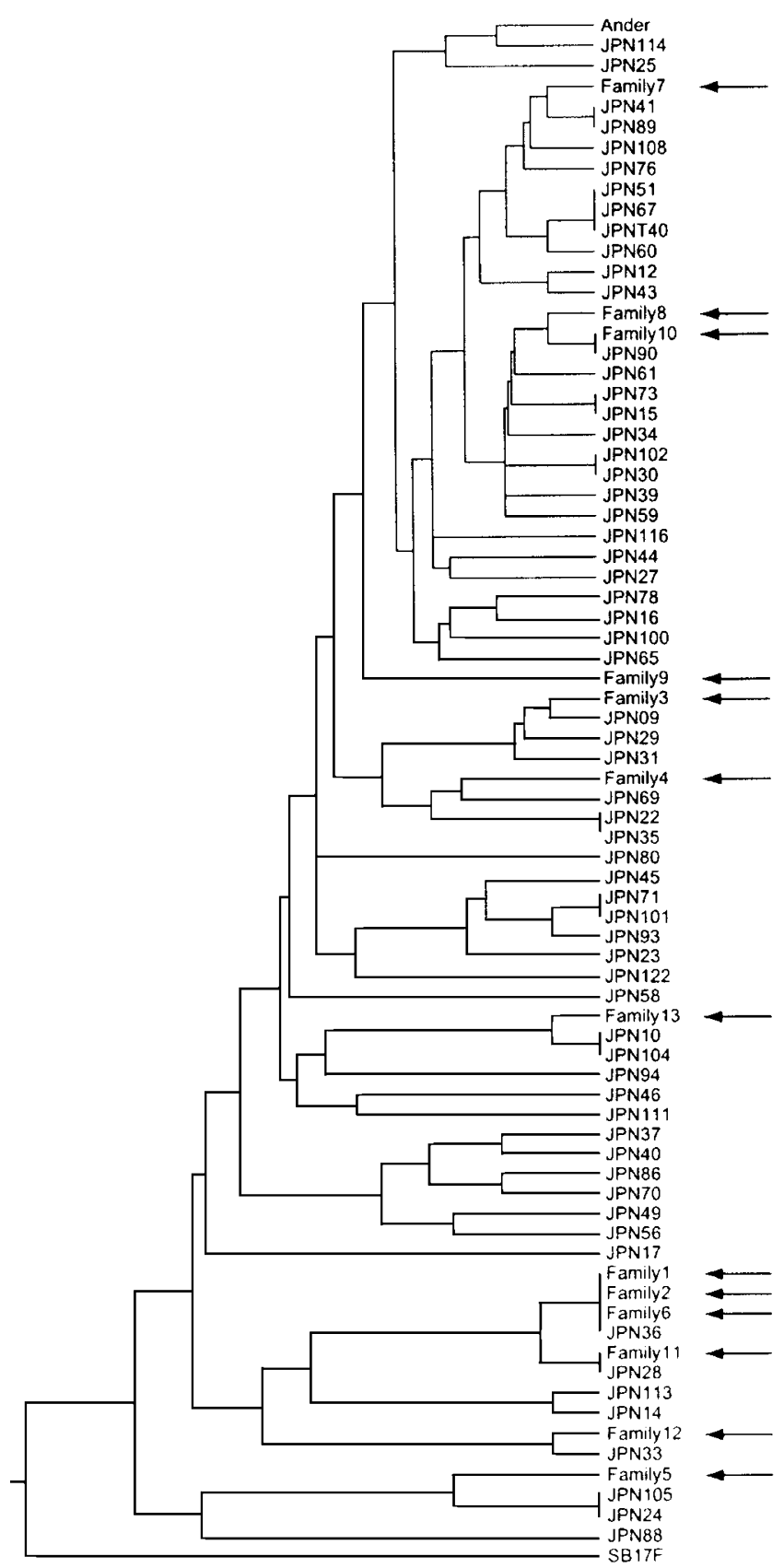

Figure 1 UPG M A -tree based on 482-bp sequences. Phylogenetic tree showing the 13 families (arrows) compared with 62 normal Japanese subjects, $1 \mathrm{E}$ uropean (A nder), and $1 \mathrm{~A}$ frican (SB 17). Three families (1, 2 and 6) belong to the same haplotype, though the remaining ten families are found throughout the phylogenetic tree.

A $1555 \mathrm{G}$ mutation may not be related to those haplogroups. In contrast to the data by $\mathrm{H}$ utchin et al ${ }^{9,10}$ who indicated that there is a high frequency of $\mathrm{A} 1555 \mathrm{G}$ carriers in persons with group II mtD NA, our data did not show any preferential occurrence of the A $1555 \mathrm{G}$ mutation in group II.
The intergenic COII/tRNA (Lys) 9-bp deletion has been reported in various racial populations with varying frequency, and to be an especially valuable anthropological marker for people of A sian origin. ${ }^{11,12,20}$ In the present study, although six out of the 13 families (46\%) showed 9-bp deletion, if families 1, 2 and 6 were to have a common ancestor as discussed later, the corrected frequency might be $36 \%$ (4/11), which is comparable with the reported frequency of $28 \%$ in northern Japan. ${ }^{25}$ Therefore there is unlikely to be a relationship between the haplogroup with 9-bp deletion and the A $1555 \mathrm{G}$ mutation.

A recent study indicated that the $D$-loop region, which is more rapidly evolved than other parts and therefore more variable, has been used as an evolutional marker. ${ }^{13}$ We therefore analysed the $\mathrm{D}$-loop region of $\mathrm{mtDNA}$ by the direct sequencing method, in addition to restriction enzyme analysis of mtD NA and the 9-bp deletion. In the present study, the sequences of the mitochondrial D-loop were variable and no common patterns were seen in the 13 families, except in three (families 1, 2 and 6) from the same region (the northern part of Japan).

Within $D$-loop sequences of the 13J apanese families studied, an $A$ to $G$ conversion at both sites 73 and 263 was commonly found. One or both of these two mutations may possibly be associated with the A 1555G mutation responsible for hearing impairment. However, since these two mutations have been reported to be relatively common in the Japanese, ${ }^{26}$ they are unlikely to be relevant to hearing impairment; in fact, non-affected family members also have those two base conversions. Further study will be necessary to determine if these two mutations are markers of a more mutagenic mitochondrion.

Mean pairwise divergence of $D$-loop in this study (mean $1.11 \%$ : range $0-1.51 \%$ ) is compatible with that previously reported in Mongoloid subjects. ${ }^{14}$ Mean pairwise divergence of the hyper variable part of the D -loop (mean $2.13 \%$ : range $0-3.51 \%$ ) is not lower than that (mean $2.2 \%$ : range $0.51-4.3 \%$ ) reported in A frican and A sian subjects bearing the A $1555 \mathrm{G}$ mutation by Hutchin et al. ${ }^{9}$ If the 13 families in this study had a common ancestor, the mean pairwise divergence would be smaller, but the variable tendency in pairwise divergence suggested the multiple mutational occurrence.

Evolutionary relationships between families represented by the U PG M A -tree based on 482-bp sequences show that families with the A $1555 \mathrm{G}$ mutation are 
distributed widely across all the postulated branches of the Japanese evolutionary tree (Figure 1). A Ithough the three families (1, 2 and 6 from the northern part of Japan) which have the same polymorphic patterns belong to the same group, the other families were found sporadically. In Figure 1, families next to each of the 13 families did not possess the A $1555 G$ mutation, suggesting this mutation may be a recent and sporadic mutational event during the mtD NA divergence.

With regard to the polymorphism found in the subjects associated with the A $1555 G$ mutation, recent phylogenetic analysis of the mtDNA of A frican and A sian patients bearing the A 15556 mutation indicated that the A 15556 mutation occurred in each racially specific mtD NA haplotype. ${ }^{9} \mathrm{R}$ esults from our phylogenetic analysis of 13 Japanese families were also compatible with the multiple occurrence of this mutation, but did not support A $1555 \mathrm{G}$ mutation occurrence on some A sian-specific haplotypes. ${ }^{9,10} \mathrm{O}$ ur data indicated that this mutation occurred sporadically during the mtD NA evolution even within the Japanese population. In addition, it is likely that some minor families may have had a common ancestor.

A s to association of disease-related mitochondrial mutations with particular haplogroups, differing results have been reported. In Leber's hereditary optic neuropathy $(\mathrm{LHON})^{27,28}$ several pathogenetic mitochondrial mutations have been reported. A mong these, some were found to be associated with some particular haplogroups and some were found to not be so. ${ }^{29}$ The A 4336G mutation, which is known to be related to A Izheimers and Parkinson's disease, was found to be associated with some particular haplogroups. ${ }^{9} \mathrm{How}-$ ever, the A $1555 G$ mutation was found in this study to be randomly distributed throughout the phylogenetic tree.

A question remains as to why the $\mathrm{A} 1555 \mathrm{G}$ mutation has been reported mainly in $A$ sian ancestry. The higher incidence of the A $1555 \mathrm{G}$ mutation in the Japanese population may be interpreted in two ways. First, aminoglycoside antibiotics were commonly used in Japan in 1950-1970. Since aminoglycoside exposure has been more common in A siatic populations, it is perhaps reasonable to expect a higher frequency of deletion of A $1555 G$-associated aminoglycoside deafness. H owever, recent wide screening in our population resulted in our finding several hearing-impaired patients bearing the A $1555 G$ mutation who had no history of aminoglycoside injection. ${ }^{4} \mathrm{~A} n$ alternative explanation is that there is some genetic background in the Japanese population which exacerbates the effect of the A $1555 \mathrm{G}$ mutation. It is possible, as hypothesised by Jabor et al, ${ }^{30}$ that there is an additional recessive gene. The involvement of a secondary mutation is another possibility that has not yet been proven.

However, the present results from three different approaches (restriction enzyme analysis, the presence of the 9-bp deletion, and the sequence of the D-loop region) did not provide evidence of any possible haplogroups which may be related to the A 1555G mutation in the Japanese population.

\section{Acknowledgements}

We are most grateful to Dr M asanori I shii and Tetsuya Tono for their valuable help in collecting data on families. The present results were presented at the 20th A ssociation for R esearch in O tolaryngology Meeting, 1-8 February 1997, St Petersburg B each, FL, USA. This study was supported by a Grant-in-A id for Scientific R esearch from the Ministry of Education, Science and Culture of Japan (SU and HS), the $\mathrm{M}$ inistry of $\mathrm{H}$ ealth and Welfare of Japan (SU), and by $\mathrm{NIH}$ NIDCD PO1 DC01813 (WJK).

\section{References}

1 Fischel-Ghodsian N, Prezant TR, B u X, Öztas S: M itochondrial ribosomal R NA gene mutation in a patient with sporadic aminoglycoside ototoxicity. A m J O tolaryngology 1993; 14: 399-403.

2 H utchin T, Haworth I, Higashi K, Fischel-G hodsian N, Stoneking M , Saha N, A rnes C, Cortopassi G : A molecular basis for human hypersensitivity to aminoglycoside antibiotics. N ucleic A cids Res 1993; 21: 4174-4179.

3 Prezant TR, A gapian JV, B ohlman MC, Bu X, Oztas S, Qiu WQ: M itochondrial ribosomal RNA mutation associated with both antibiotic-induced and non-syndromic deafness. N at G enet 1993; 4: 289-294.

4 U sami S, A be S, Shinkawa S, Moeller B, Kenyon JB, $\mathrm{K}$ imberling WJ: Genetic and clinical features of sensorineural hearing loss associated with the 1555 mitochondrial mutation. L aryngoscope 1997; 107: 483-490.

5 Fischel-Ghodsian N, Prezant TR, Chaltraw WE et al: $M$ itochondrial gene mutation is a significant predisposing factor in aminoglycoside ototoxicity. A m J O tolaryngology 1997; 18: 173-178.

6 M atthijs G, Claes S, L ongo-M benza B, Cassiman J J : Nonsyndromic deafness associated with a mutation and a polymorphism in the mitochondrial $12 \mathrm{~S}$ ribosomal RNA gene in a large Z airrean pedigree. E ur J H um G enet 1996; 4: $46-51$.

7 Estivill X, Govea N, Barceló A, Perelló E, Badenas C, R omero $E$, M oral L, Scozzari R, D 'U rbano L, Zeviani M, Torroni A : Familial progressive sensorineural deafness is mainly due to the mtDNA A $1555 G$ mutation and is enhanced by treatment with aminoglycosides. A m J H um G enet 1998; 62: 27-35. 
8 Pandya A, Xia X, Radnaabazar J: Mutation in the mitochondrial 125 rRNA gene in two families from Mongolia with matrilineal aminoglycoside ototoxicity. J Med G enet 1997; 34: 169-172.

$9 \mathrm{H}$ utchin TP, Cortopassi GA : Multiple origins of a mitochondrial mutation conferring deafness. Genetics 1997; 145: $771-776$

10 H utchin T, Cortopassi G : M itochondrial DNA haplotype predicts deafness risk. A $\mathrm{m}$ J M ed $\mathrm{G}$ enet (Neuropsychiatric Genetics) 1995; 60: 592.

11 Wrischnik LA, Higuchi RG, Stonecking $M, E$ rlich $H A$, A rnheim $N$, Wilson $A C$ : Length mutations in human mitochondrial DNA; direct sequencing of enzymatically amplified D NA . N ucleic A cids Res 1987; 15: 529-542.

$12 \mathrm{H}$ ertzberg $M$, M ickleson KNP, Serjeantson SW, Prior J F, Trent RJ: A n A sian-specific 9-bp deletion of mitochondrial DNA is frequently found in Polynesians. A m J H um G enet 1989; 44: 504-510.

13 Howell N, Kubacka I, Mackey DA : H ow rapidly does the human mitochondrial genome evolve? A m J H um G enet 1996; 59: 501-509.

$14 \mathrm{H}$ orai $\mathrm{S}, \mathrm{H}$ ayasaka $\mathrm{K}$ : Intraspecific nucleotide sequence differences in the major noncoding region of human mitochondrial DNA. Am J $\mathrm{H} u m$ Genet 1990; 46: 828-842.

15 Torroni A, Schurr TG, Cabell MF, Brown MD, Nell JV, Larson $M$, Smith DG, Vullo CM, Wallace DC: A sian affinities and continental radiation of the four founding native A merican mtDNA s. Am J Hum Genet 1993; 53: 563-590.

16 A nderson $S, B$ ankier $A T, B$ arrell $B G$, Bruijn $M H L$, Coulson A R, D rouin J, E peron IC, N ierlich D P, R oe BA, Sangre F, Schreier PH, Smith A J H, Staden R, Y oung IG: Sequence and organization of the human mitochondrial genome. Nature 1981; 290: 457-465.

$17 \mathrm{H}$ orai S, Matsunaga E: M itochondrial DNA polymorphism in Japanese II. analysis with restriction enzymes of four or five base pair recognition. Hum G enet 1986; 72: 105-117.

18 M erriwether DA, R othhammer F, Ferrell RE : M itochondrial DNA variation in ancient and contemporary A merindians using the tR NA ${ }^{\text {LYS }}$-COII deletion and diagnostic restriction sites. A m J H um G enet Suppl. 1992; 53: 833.

19 Merriwether DA, Hall WW, Vahlne A, Ferrell RE: $m t D N A$ variation indicates $M$ ongolia may have been the source for the founding population for the N ew World. A m J Hum G enet 1996; 59: 204-212.
20 Horai S, M urayama K, Hayasaka K, M atsubayashi S, $\mathrm{H}$ atorri $\mathrm{Y}$, Fucharoen $\mathrm{G}, \mathrm{H}$ arihara S, Park K S, O moto $\mathrm{K}$, Pan IH: mtD NA polymorphism in east A sian populations, with special reference to the peopling of Japan. A m J H um G enet 1996; 59: 579-590.

$21 \mathrm{~K}$ imura $\mathrm{M}$ : A simple method for estimating evolutionary rate of base substitutions through comparative studies of nucleotide sequences. J M ol E vol 1980; 16: 112-120.

22 Nei M: Molecular Evolutionary G enetics. Columbia U niversity Press: New York, 1987, 293-298.

23 Harihara S, Saitou N, H irai M, Gojobari T, Park KS, M isawa S, E Ilpola SB, I shida T, O moto K: M itochondrial D NA polymorphism among five $A$ sian populations. A $\mathrm{m} J$ H um G enet 1988; 43: 134-143.

$24 \mathrm{H}$ orai S, Gojobori T, M atsunaga E : M itochondrial DNA polymorphism in Japanese I. analysis with restriction enzymes of six base pair recognition. H um G enet 1984; 68: 324-332.

25 H orai S: In: K imura M, Takahata N (eds). N ew A spects of the $G$ enetics in Molecular Evolution. Japan Scientific Societies Press: Tokyo/Springer-Verlag: Berlin, 135-152, 1991.

26 Stoneking $M$, Hedgecock $D, H$ iguchi $R G$, Vigilant $L$, Erlich HA: Population variation of human mtDNA control region sequences detected by enzymatic amplification and sequence-specific oligonucleotide probes. A m J H um G enet 1991; 48: 370-382.

27 Brown MD, Torroni A, Reckord CL, Wallace DC: Phylogenetic analysis of Caucasian 11778-positive and 11778-negative L eber's hereditary optic neuropathy mitochondrial DNA s indicates multiple independent occurences of the common primary mitochondrial DNA mutations. H um M utat 1995; 6: 311-325.

$28 \mathrm{H}$ owell N, Kubacka I, Halvorson S, H owell B, M cC ullough DA, Mackey D: Phylogenetic analysis of the mitochondrial genomes from Leber hereditary optic neuropathy pedigrees. G enetics 1995; 140: 285-302.

29 Torroni A, Petrozzi M, D 'U rbano L, Sellito D, Zeviani M, Carrara F, Carducci C, Leuzzi V, Carelli V, Barboni $P$, Negri AD, Scozzari R: Haplotype and phylogenetic analyses suggest that one European-specific mtDNA background plays a role in the expression of Leber hereditary optic neuropathy by increasing the penetrance of the primary mutations 11778 and 14484 . A m J H um G enet 1997; 60: 1107-1121.

30 Jabor L, Shohat M, B u X, Fischel-G hodsian N, Y ang HY, Wang S], R otter JI: Sensorineural deafness inherited as a tissue specific mitochondrial disorder. J Med G enet 1992; 29: 86-90. 